\title{
5. Developing innovation policy
}

\subsection{INTRODUCTION}

In Part II, so far, selected innovation policies were reviewed in Chapter 3 and ways of monitoring or evaluating innovated policies were discussed in Chapter 4. In both cases, and in this chapter, innovation policy is focused on the business sector. The question now is how innovation policy has been developed. This can occur as a result of the evaluation of existing policies, such as those in Chapter 3, with a view to improving the outcomes. An alternative approach is the development of an entirely new innovation policy to address new objectives.

In the business sector, innovation policy, initiated by government, is expected to deliver good jobs, economic growth and other important outcomes such as wellbeing. How policy is designed to deliver these objectives is an issue and the approach is not the same in all countries. In a previous discussion of developing innovation policy (Gault 2010), the distinction was made between countries that took 'a whole of government' approach and those that had fragmented policies which varied from ministry to ministry. As an example, one ministry could promote R\&D performance while another promoted the use of information and communication technologies (ICTs). There are overlaps which may cause problems if the ministries do not communicate with one another.

Innovation policy can also be part of a regional development policy, promoting innovation in developing regions (European Commission 2019) in the hope that the underdeveloped regions can catch up with the more prosperous ones. There is sectoral innovation policy, promoting innovation in agriculture, ICTs, bio- and nano-technology, artificial intelligence, or other technologies that are giving rise to the "fourth industrial revolution' (Schwab 2017, 2018). There is 'restricted' innovation which is used to identify a measurement of innovation with a particular characteristic, such as inclusiveness or sustainability.

A decade ago, countries were trying to deal with the consequences of the financial crisis of 2008 and policy makers were looking to inno- 
vation policy for ways out of the crisis and to support recovery. At the time, there was limited discussion of the cause of the crisis being the introduction on the market of new or significantly improved financial products, based on sub-prime mortgages, as there was a belief, still prevalent, that all innovation is good. In that period, there was little discussion of innovation as a systems phenomenon outside of the scholarly community (Edquist 2005). A systems approach to innovation policy (Chapter 2) includes direct intervention to change the behaviour of firms, indirect intervention to change the framework conditions that influence innovation in the firms (trade regulation, rules governing employment, higher education outcomes ...) and, of considerable importance, policy intervention to change the flows of knowledge, material and human resources into and out of firms. This is not a criticism of research on national innovation systems, but a more general observation about the use, or lack of use, of a basic systems approach to describe innovation in firms, the innovation activities engaged in by the firms, linkages with other economic institutions and the outcomes and impacts of innovation policy, once implemented.

Edler and Fagerberg (2017) separate innovation policy into three categories. The first, citing Ergas (1986), is mission-oriented innovation policy such as DARPA's creation of the internet which has had significant economic impact (Mazzucato 2013). The purpose of the implemented policy was to solve a problem and the work was done by a public sector organisation. Public sector innovation is an important issue which will be considered in greater detail in Part III and global challenges, more specifically, in Chapter 9.

The second is invention-oriented innovation policy driven by $\mathrm{R} \& \mathrm{D}$, which has been referred to as R\&D, research, or science policy as well as innovation policy. This is an issue in countries with a small private sector where governments are more inclined to create and support research institutions and university departments.

The third category is system-oriented policy which was introduced in Chapter 2, along with National Innovation Systems. This book takes the view that all innovation policies need to take a systems approach as innovation is a systems phenomenon (Chapter 2).

Since the financial crisis of 2008 there have been major changes in the activity of firms as the economy has become digital. That was not an issue in 2008, but it is now, and there are implications for policy (Guellec and Paunov 2018) and statistical measurement (OECD 2019a) to support policy development. 


\subsection{GOVERNING INNOVATION POLICY}

In Chapters 2 and 3, the point was made that innovation is a systems phenomenon and innovation policy development must take that into account if it is to be effective when it is implemented. Borrás and Edquist (2019: 232) argue the case for 'holistic innovation policy' which includes all parts of the innovation system. The OECD Innovation Strategy (2015a) notes the utility of 'a whole of government' approach to innovation policy. This was also discussed in Gault (2010) from an operational perspective dealing with the policy instruments that can be used to implement an innovation policy, whether a partial one in a single ministry or a whole of government approach.

For there to be a whole of government approach to innovation policy, the lead must come from a high level. In some countries this can work, but in others not. Consider the review of innovation policy and indicators in the US provided by Christopher Hill (2013). John Marburger, at the OECD Blue Sky Forum-2, addressed the whole of government approach as follows:

Overall science planning and policy making is accomplished through a bewildering variety of advisory panels, interagency working groups, and Executive Branch policy processes, the most important of which is the annual budget process that synthesizes the proposal presented annually by the President to Congress. In Congress, multiple committees and subcommittees authorize and appropriate funds in an intense advocacy environment from which politics is rarely excluded. (Marburger 2007: 30)

Whether the policy is whole of government or limited to one ministry, once it has been implemented statistical measurement may be considered so that the policy can be monitored and, eventually, evaluated. This would support policy learning leading to changes to the policy to make it more effective.

For a number of reasons, the governance of innovation policy has changed over the last decade and Edler and Fagerberg (2017) have provided a review of innovation policy which addresses: what innovation policy is; why there is an innovation policy, with a discussion of theoretical rationales; and innovation policy in practice. 


\subsection{MEASURMENT AND RESTRICTIONS}

This book is about statistical measurement of innovation and in Part II, the focus is on innovation in firms and the Community Innovation Survey (CIS) and CIS-like surveys are the measurement examples. This section deals with methodological constraints and restrictions which are, or could be, part of the measurement. Restrictions are important as they help to respond to policy questions that go beyond an interest in the propensity of firms to innovate.

An example of a methodological constraint on a survey is the three-year reference period for observing innovation in CIS. Consider the following question, 3.1, from the CIS 2018 survey:

During the three years 2016 to 2018, did your enterprise introduce any:

New or improved goods Yes/No

New or improved services Yes/No

The question, 3.1, is prefaced with: 'A product innovation is a new or improved good or service that differs significantly from the firm's previous goods or services and which has been implemented on the market'. This differs from the definition of innovation in the 3rd edition of the Oslo Manual (OECD/Eurostat 2005), and from the definition of business sector innovation in the 4th edition (OECD/Eurostat 2018). This reflects the fact that the question was drafted in the middle of three years of revision of the Oslo Manual. That is not an issue, but the constraint, 'During the three years 2016 to $2018^{\prime}$ ' is. This is also discussed in the Oslo Manual (OECD/Eurostat 2018: Chapters 3, 9 and 11).

A firm that introduced on the market a new or improved product on 31 December 2015 is not an innovative firm in the CIS 2018 unless there is a new innovation within the period 2016-18. This can be a concern to firms that have invested in the new product and brought it to market only to find that they cannot report this in their response to the questionnaire as the innovation was out of scope. If the firm was in the sample for the CIS 2016, the firm would be recorded as an innovative firm, but not for CIS 2018.

In addition to methodological constraints, there are restrictions that may be imposed on the measurement of innovation as they are of policy relevance. The minister is not looking for the propensity of firms to innovate but the influence of innovation policy on key issues of the day. Reporting on the likelihood of innovation to advance sustainability and 
inclusion are examples, so are jobs and growth. They will be introduced here and discussed further in Chapter 9.

A first requirement is that there are definitions of sustainability and inclusion and of the population to be studied. Is the issue of sustainability economic, environmental or social or a combination of all three? Once those questions are answered, survey questions can be drafted, questionnaires designed, and measurement made. The same applies for inclusion. What is to be included (the poor, poorly served social groups, adherents of other cultures, women, ...)?

There are two approaches to measuring these innovation restrictions (Gault 2018a). The first is the provision of a product innovation and the impact on the users of that product. To determine a change in inclusion or sustainability the users must have been surveyed and these could be surveys of any economic sector. For household products, social surveys would be required. The second approach is process innovation and the resulting impact - is it inclusive and sustainable and is there a causal link between the process innovation and the perceived outcome?

\subsection{INTERNATIONAL INNOVATION POLICY}

Innovation policy can come from international or supranational organisations. The OECD Innovation Strategy (OECD 2015a) has already been discussed and the importance of 'a whole of government' approach. Since 2015 there has been a rapid change to the digital economy and the OECD's Digital and Open Innovation Project has produced reports on the digital economy (OECD 2017e), innovation policy (Guellec and Paunov 2018; OECD 2019a) and measurement (OECD 2019d). A point to note is that the OECD provides working examples of innovation policy, but it does not propose innovation policies for Member Countries.

The European Commission provides an approach to innovation policy in a number of domains not all of which are covered by the third edition of the Oslo Manual (OECD/Eurostat 2005). They are:

- social innovation

- demand-side innovation policies

- public sector innovation

- workplace innovation. 
It is evident that the European Commission sees these topics as significant, even if the measurement mechanisms, including definitions, are not present for all of them to support monitoring and evaluation.

There is also the Enhanced European Innovation Council (EIC) pilot. It brings together the parts of Horizon 2020 that provide funding, advice and networking opportunities for entrepreneurs and innovators.

In a third example, the African Union (AU 2014) has published a Science, Technology and Innovation Strategy for Africa (STISA 2024). It expects Member States to implement the strategy, to agree on indicators and to report on the findings of statistical measurement. STISA - 2024 is part of a longer term initiative, the Agenda 2063.

\subsection{CONCLUSION}

In this chapter approaches to developing innovation policies were reviewed from the country level and from that of international/supranational organisations, the African Union, the European Union and the OECD.

The focus has remained on innovation in the business sector, but with some reference to the need to measure innovation, viewed as a systems phenomenon, in all economic sectors.

The principal change in the economy in the last decade is digitalisation which has been introduced. What has not been discussed, now that there is a clear need for measuring innovation in all sectors, is how to define innovation to support policy making and measurement. That follows in Part III.

\section{NOTES}

1. Chaminade et al. (2018) provides a thorough review of the subject. See also Soete et al. (2010).

2 The reader may find that not all ministries support monitoring or evaluation of their policy interventions.

3. See https://ec.europa.eu/growth/industry/innovation/policy_en (accessed 17 March 2020).

4. See https://ec.europa.eu/research/eic/index.cfm (accessed 17 March 2020). 